\title{
Analysis on the Sustainability of Home Supplies Design
}

\author{
Quanheng Li \\ Guangdong Industry Polytechnic \\ Guangzhou, China 510300
}

\begin{abstract}
Sustainability is very important for the globe, a country and a trade, and designers should bear the social load and responsibilities for sustainable design. In order to well control three backbones namely society, environment and economy, we should make them support and promote each other and jointly promote the sustainable development, making the sustainable development of home supplies be a new normal.
\end{abstract}

Keywords-home supplies; design; sustainable; analysis; economic benefits

\section{INTRODUCTION}

The sustainability of home supplies plays a crucial role in promoting the long term development of the industry. And the construction of home supplies brands will be a great support to the sustainable construction of the whole home supplies industry, which also exerts the brand value function and improve the product quality. The brand construction is one of the reasons for the sustainable development of home supplies, the sustainability is a simple concept, which consists of a string of complicated factors and contains a lot of work to be done.

Sustainable development is a precondition to meet the needs of the people in modern society, which shall not destroy the need or waste the resources of next generations, the sustainability is a complicated thought, which cover all parts of the human thought, influencing the society, environment and economy. When the concept of sustainable development has been completely recognized by the people, we should know what we should do and what not. It is said that home supplies stay with us, and we should try our best to promote the home supplies design to be sustainable. Just like what An. Sopo said, sustainable design creates conditions for ecology, economy and culture, bringing humans limitless happiness.

With the deepened understanding of sustainable development by the people, consumers have paid more and more attentions to low-carbon and environment friendly products, especially young people who were born in the $1970 \mathrm{~s}$, the 1980s and the 1990s highly value the sustainability development concept. So to add the sustainable development concept to the home supplies design will do good to the mark development of creative home supplies. The sustainable development concept integrates our concerns about the sustainable development of home supplies industry and home supplies design to the home supplies design. In fact, what we are concerned about is how to apply the sustainable development concept in the design and development. For the sustainable development brings a challenging way for the home supplies design, showing the way for innovative design to break through, which are of great significance for home supplies industry, society, environment and economy.

\section{SUSTAINABLE ECO DESIGN}

\section{A. Eco Design}

Green design, the thought of fashionable design was raised early in the 1920s, at the end of the 1990s, some designs with diverse styles have been bottlenecked, the green design concept is a deeper level that designers can prolong the sustainable development to a new level, for which, a mechanism is formed to support the coordinative development between the society, environment and economy. The appearance of green design symbolizes that environmental protection should be fully considered during the design, and more attentions should be paid to solutions of single problem such as energy consumption or material selection. Designers start to tend to natural materials, economics of materials, and use of recyclable materials and so on, which turn out that designers have taken environmental protection into their design, showing consciousness to green design promotion.

Based on green design, eco design furthers its attentions to environmental problems, which will consider not only the eco influences of home supplies but also the life cycle of whole home supplies. For some home supplies will cause severe influences on the environment around, for example, the home supplies related to electric appliances will cause severe influences on the environment during the use. So designers should be focused all stages of the whole life cycle of home supplies, connect the results in every stage of the product development with environmental problems for consideration in order to minimize the negative influences and destroy to the environment as possible as we can

\section{B. Responsibility Design}

Social responsibilities of an enterprise are not limited to products, service, as well as the direct influences of service 
system on the environment and society, there are more problems it should solve, and for example, it should take charge to solving social education, healthcare and crimes through design. Design can be used for environmental education, making the people reflect on the environment destroyed by excessive sizes of resources; with some policies adopted, the production responsibility system is carried out really, and all industries are promoted to control and dispose refuses. Currently it is time of commodity with a great number of production and sales, the renewal period of diverse home supplies is shortened increasingly, and how to recycle the products has become a tough problem. How to make the designed and manufactured home supplies upgrade and continue the value at the end of its service life, or during the design and material selection and production, renewable resources shall be selected as possibly as we can in order to keep it harmless in drainage.

In 1994, Sweden carried out production responsibility system in some enterprises, achieving the responsibility distribution from product process to the final consumption, which made an obvious effect. At the beginning, the system was only carried out in industries such as product packaging and waste paper; afterwards, it spread to auto, office paper, agricultural plastic, electronic and electric appliances, rejected cells and so on, which was modified for improvement. The system mainly stated environmental responsibilities that manufacturers should take for some rejected resources in production and recycling after the final product consumption. As such, while designing products, the manufacturers will consider relevant recycling and follow-up disposal in order to avoid or reduce the damages the products bring to the social environment.

Therefore, domestic enterprises and designers should take full responsibilities for the society, deeply recognizing that the ultimate goal that the home supplies processed under design should avoid or reduce the influences on the environment while bring economic value, and better occupying home supplies market and keeping the sustainable development of home supplies.

\section{ECONOMIC BENEFITS OF SUSTAINABLE DEVELOPMENT}

It has been widely recognized that rapid growth and development of domestic economy and home supplies manufacturing have brought severe influences on the social environment. Most recently, some design concepts and eco strategies related to sustainable development have appeared such as eco design and low-carbon design in order to improve the social environment, which have become hot focuses in many educational institutions and enterprises, and opportunities for home supplies in the economic development in the future. When low carbon and eco are taken as typical important symbols for the development of the society, economy and culture, the argument between theories and practices of sustainable design is hot as well, so do the home supplies design.

Seen from rational use and economic benefits of materials, in addition to selecting environment friendly materials, there are other materials that can bring economic benefits to enterprises such as industrial residuals, residuals in process, second hand materials and so on. To recycle the materials and upgrade will bring considerable economic benefits to enterprises. With the increasing competition in home supplies markets, how to get high earnings with low costs has become a problem urgent to be solved by enterprises. Traditionally, what sustainable design initiates is reduction, reuse and recycling, which is one of the best method to solve the problem. With regard to the wastes, leftover materials, if they can be reused rationally and skillfully, no doubt it will increase the enterprises' economic benefits, showing also a concept of low carbon and environmental protection. As what shown in Fig 1, ancient ship wood is used for furniture material in design, and the leftover materials after completion of furniture making can be reused and processed as exhibits, then the remaining will be processed into small pieces as mosaic used in diverse spaces. Big block of ancient ship wood can be used for furniture making, and the materials keep tracks with nails removed, a beauty of flaw; the leftover materials also have features when used for exhibits, and the smallest remaining is processed into mosaic which are characterized of high decoration, wear resistance, damage resistance, water tight and so on, which can be widely used through massive production and sales in "Fig. 1".



Fig. 1. Leftover upgrades and recycling, Picture Source: Baidu.

\section{Sustainable Memory in Culture}

During the current design, in order to keep the inherent characteristics of single material, combine it repeatedly and regularly and achieve the impression breakthrough through quantity accumulation and senses of forms, we should exert the value of waste materials in memory of culture. Waste materials are used ones, which get involved the historic culture and background stories of their own. It ever witnessed the culture in a certain stage, containing the living records of that time; the development of waste materials in memory of culture can further reflect the value of recycling the waste materials, showing the real significance of waste materials for sustainable development.

Memory of culture is reserved through symbols, and the memory of culture related to waste materials requires that designers should reserve the tracks of waste materials, process and delivery to consumers. The tracks may be a historic culture and section of some memory or a living style, long lost episode or known habits; in a word, all of the waste materials carry some memory of culture, which can bring consumers different impressions or emotions, reminding consumers of some memories different. 
The memory of culture that waste materials carry is one of the inspirations for designers to design, which is a cultural essence for creativity delivery. Waste materials are outdated, which we ever understood or touched can be reused, whether they can deliver consciousness of modern society, represent the memory of culture and background stories from new home supplies or not should be further thought by designers. In recent years, with the improvement of the public's awareness in eco and environmental protection, the design trend of recycling waste materials is promoted, and designers have paid more attentions to the memory and inheritance of cultural symbols of waste materials. Waste materials have some history and deposition, whose background stories and memory of culture both can remind consumers of deep-level understanding of eco and environmental protection, and the cultural symbols of waste materials are memorized and inherited for renovation and design during the home supplies design.

As what shown in "Fig. 2", the belt carries the history of waste tyre, which has traces when used as tyre or collided, the designer HOWIES reserved the memory of culture, showing it through creativity and uniqueness, from which consumers can get it and understand the background story of it.



Fig. 2. Polished recycling belt.

$$
{ }^{\text {a. }} \text { Picture source: self-owned. }
$$

\section{CONCLUSION}

In a word, sustainability is a simple mode, and it controls three backbones namely society, environment and economy, which depend on and support each other to promote the sustainable development, which is also a goal of home supplies aimed at sustainable development. Home supplies may change consumers' attitudes and behaviors while meeting the need of consumers. Therefore, the sustainable development of home supplies requires that designers should consider the design of home supplies sustainability for diverse aspects. Currently the sustainable design of home supplies is an innovation challenging and break-through, which is a crossing subject with higher creativity, requiring designers to be responsible for the real world design of consumers. The sustainability design occupies a certain share, able to influence the design creativity and market.

\section{REFERENCES}

[1] Peng Sizhen, Sun Xinzhang, Global Sustainable Development Report: Background, Progress and Suggestions [J]. China Population Resources and Environment, 2014, 11: 1-5.
[2] Li Quanheng, Collaboration Brings Innovation ---- The Teaching Research and Practice of Design on Recycling of Waste Materials[M].ICELAIC 2014 Conference Proceedings, ISBN(online): 978-94-6252-013-4, 2014, 05: 52-55.

[3] Li Quanheng, Waste Recycling Innovative Design in Home Decorations Design [J]. Design, 2014, 07: 190-191.

[4] Su Fei, Ying Rongrong, Zeng Jiamiao, Research on Sustainable Livelihoods and Visualization Analysis [J]. Acta Ecologica Sinica, 2016, 07: 2091-2101.

[5] He Yun, Ouyang Bo, Consumers-based Research on Home Supplies Design under Low-Carbon Environment [J]. Packaging Engineering, 2016, 02: 65-68.

[6] Liu Hui, Research on Feasibility of Water Hyacinth in Home Supplies Design [J]. Art Education Research, 2016, 11: 64-65. 